\title{
What is learned during the first moments of work?
}

\author{
Claire Tourmen ${ }^{\mathrm{a}, *}$, Annie Leroux ${ }^{\mathrm{b}}$ and Sylvie Beney ${ }^{\mathrm{c}}$ \\ a AgroSup Dijon, 26 Bd du Dr PetitJean, 21000 Dijon, France \\ ${ }^{\mathrm{b}}$ CARSAT de Bourgogne, Service social, 37 rue Gérot, 89000 Auxerre \\ c Conseil Général de Saône et Loire, Espace Duhesmes, 71000 Mâcon, France
}

\begin{abstract}
The supervision of internships is often based on common sense. However, learning processes at workplace and their conditions remain partly unknown: what is really learned and under what conditions? Two studies on the learning of social working have been conducted, based on work analysis theories and methods. 6 experienced social workers and 4 interns in their first year of training have been interviewed according to the method of "explicitation" interview. The results show that professional learning can occur anyplace, anytime, under certain conditions and under certain forms that have been analyzed. These studies try to analyze the first internship as an entrance into a culture, through a psychological perspective.
\end{abstract}

Keywords: professional learning, internship supervision, work analysis, professional didactics, culture

\section{Learning at work place: the case of social workers}

The supervision of internships at workplace is often based on common sense. It is commonly believed that an intern will learn by observing a more experienced professional and by doing. The underlying hypothesis is that any work activity is "productive" and "constructive" at the same time [7]. However, learning processes at workplace and their conditions remain partly unknown: what is really learned and under what conditions? What are the roles of observation, action and supervision in these processes? If many studies have been done on the differences between novices and experts, fewer have been done on learning processes at workplace, in real conditions.

These questions are a going concern in organizations hosting interns, as in social work. Since a recent reform $\left(29^{\text {th }}\right.$ of June 2004), they shall design intelligent internship paths and improve their supervision.

To examine these questions further, two studies have been conducted, based on work analysis theo- ries and methods as used in the French tradition of ergonomic studies [4]. They also referred to a theory of professional learning developed in professional didactics [6] and to a theory of culture developed in cultural psychology [8]. The aim was to identify what is learned during a first internship at workplace and what conditions may favour or hinder this learning process.

\section{Two studies on the learning of social working}

Two studies on the learning of social working were carried out within two institutions. The first was a Department (a Conseil Général, that is a French territorial division in charge of social programs) and the second was a regional agency of the French health insurance fund (CARSAT, ex CRAM). Interns are regularly hosted in these two organizations. While following a 3 years course to become a "social worker" (assistant de travail social), students have to carry out, each year, a period of internship in organizations that employ social workers.

\footnotetext{
E-mail of corresponding author: Claire.tourmen@educagri.fr
} 
The work of a sample of experienced social workers has first been studied through ergonomics methods, in order to identify the tasks that are to be performed and learned. After having analyzed the prescription (according to Leplat's method, [4]), the activity of 6 social workers has been analyzed. Field observations were impossible for confidentiality reasons. Professional's activity has therefore been accessed through "explicitation" interviews [10]. "Explicitation" interviews follow a specific protocol, used and developed in research contexts, to guide the subject to an introspective posture, in order to access pre-reflective knowledge, partially unconscious for subjects themselves and deeply embedded in action. Professionals were also asked about their supervision of interns.

Then, the activity of a sample of interns was analyzed, while they first encountered their future professional world. After having identified the tasks they had been given, 4 students (in their first year of training) participated to "explicitation" interviews in order to explore their activity and to characterize what they were learning.

\section{Results}

\subsection{Becoming a social worker: learning how to deal with users and choosing ones' working style}

Social workers are asked to improve people welfare and social well being. Through work analysis, 7 main work situations - or tasks - that are to be faced as a social worker have been identified. 3 of them (To prepare an interview with a user, To carry out the first interview with a user and To do social support) have been identified as core situations. They are of primary importance in the profession: the helping relationship with users is being built here. Social workers diagnose users" "demands" and "situations". These concepts appeared to be important in activity, especially the proprieties of emergency of the demand, implicit/explicit demand, relevant to social work support, isolated difficulty or difficulty linked to the global situation of the person.... Social workers try to propose solutions and support meanwhile developing people's "autonomy". They also aim at creating a climate of "confidence" with the users. They have to deal with a variability of users who are in different situations, express different demands that are more or less complex to solve.
There is also a variability of practices between professionals (the way to conduct an interview, for instance) that is usually accepted. Everyone does it his/her own way and all ways seem therefore to be equal, even if they are supposed to follow professional rules and principles. The work analysis therefore showed that social work is a dynamic co-activity performed with users who play a central role. How do young social workers learn to deal with them? The analysis also showed that there is not "one best way" but that there are different ways to act as a social worker, according to the variability of situations and to the professional rules and principles. How does a young professional situate him/herself within the different working "styles" [2]?

\subsection{A common pattern for work discovery: from observation to action}

There is an implicit progression of the tasks that are devoted to the interns, in the two organizations, even if there are some slight variations according to the supervisors. Interns begin by observing a variety of situations and, sometimes, reading information on the organization they are in. Then, they perform an interview with a user (core task in the profession), in a relative autonomy or even in complete autonomy. Supervisors usually avoid situations that seem too complex to them. They don't want to "undermine" the confidence of interns and users. They also diagnose the intern's capacities (the "way they respect the users", their "ability to listen", for instance) and their "autonomy" in order to adapt their tasks. Supervisors finally diagnose their "motivation" to be here and try to reinforce it in case the intern has not chosen to be here (he/she didn't find another internship for instance).

Most of the supervisors also create moments for professional transmission while working (helping to prepare an interview, for instance) and outside working (debriefing in order to "discuss the situations"). However, all the supervisors suffer from a lack of time to host interns and some of them have difficulties to stand back from their daily activity and put it into words (as one said, "we do a lot of automatic things", and interns sometimes have difficulties to understand "what is going on through their head" while acting). 


\subsection{Learning begins at the first minute and occurs in many ways}

Professional learning may occur anytime, anyway, during all the situations that are offered to the interns. The studies show that they may begin to learn as soon as they enter into the organization, as soon as they observe, even before the supervisor begins to play his/her role.

Their first contact with the professional world of social workers can be described as an entrance into a culture (specific to a profession, but also to a team and to an organization). As an intern said, "social workers have their specialized terms, which seem obvious to them, and which are not". As another said, "it is not always easy to find one's position" within a working team.

The analysis shows that the interns:

1) build first action rules and pragmatic concepts $[9,5])$ useful to perform certain tasks, such as "one shall be curious about the whole situation of the person and not only about the problem as it seems to be at the first look". They use the concepts of "situation" and "problem" which organize the way to conduct an interview;

2) they begin to conceptualize some of the situation dimensions they have to face, and especially the most central of them, the users. An intern has been surprised by the aggressiveness of a user and by the way the social worker was reacting to it (speaking calmly...), she was also surprised to hear a social worker agree with a user accusing her of being useless... she therefore discovered "the real", what resists to one's power, what has to be dealt with [3] and how some people try to cope with it.... The discovery of users, their problems and attitudes also provokes emotions. If some interns learn how to "work" on them, some of them have difficulties doing it;

3) begin to build a representation of their role/position as a young professional (related to users but also other professionals...). They are really worried about finding one's position in the working team as soon as the enter it and they seek for it. They also discover the different roles/positions that exist within a team and some of the rules that regulate the way of living together, for instance a rule of mutual support and solidarity between colleagues, also a fact such as ty between colleagues, also a fact such as “everybody doesn't love everybody in social work". They also discover that the team manager has a real role in work;

4) They also build confidence in their own capacities and develop interest for the job or some parts of it.

\subsection{An entrance into a culture}

Entering into a profession is therefore similar to a process of entering into a "social role" [8], as defined in a group, a culture. Discovering a role is also discovering "scenes" or "action patterns" [1] where this role has to be played and that promotes actions and discredits others. For instance, interns discover the scene "interview" and the way a social worker behaves and avoids to behave in front of a user. They also discover the scene "team meeting" and the action rules that structure it. Moreover, they discover ways to name things and professional signs used in a work culture. Their use can indicate professionalism. Furthermore, they discover local rules of discussion that regulate the interactions within a group. Valsiner identify them as "semiotics demand settings" [8] that structure what can be said and the way to speak about it. Young social workers especially discover - with some surprise - the changing frontiers of "professional secret" and what can be talked about during an interview with a user, and what cannot be talked about.

Yet, the interns suffer from a profusion of information and activities during their internship. They observe and do many things but miss time to analyze them with their supervisors and draw lessons from them. Many things are also seen as important but not really understood, as the institutional dimension of work and its evolutions. Moreover, they observe different working styles amongst the professional, without always having the occasion to discuss them. One concludes that "there are no good or bad rules, I think, personality has much importance...". Isn't there a risk of avoiding any discussion on practices and therefore understand, maybe change or improve them?

\section{Conclusion}

According to these studies, one can suppose that some variables have an influence on professional learning at workplace, such as: the situations and 
tasks that are offered to live and their degree of difficulty, their progression, the level of autonomy, the nature of help offered by the supervisor, the possibility to put different practices into debate...

Unfortunately, the study remained exploratory. We could not go further on these questions because of a reduced sample and because of the impossibility to go and observe people working.

Nevertheless, it helped the two organizations to 1) understand what is learned while doing an internship, 2) design the organization and the progression of tasks for the interns, 3) open a space for the discussion and comparison of different practices. One can therefore see how ergonomics approach of real work can spark off a controversy within professionals... a guarantee to keep professions alive [2]?

\section{References}

[1] J.S. Bruner, Le développement de l'enfant : savoir faire, savoir dire, Paris, Puf, 1996.

[2] Y. Clot, La fonction psychologique du travail, Paris, Puf, 2000.

[3] C. Dejours, L'évaluation du travail à l'épreuve du réel. Critique des fondements de l'évaluation, Paris, Inra Editions, 2003.

[4] J. Leplat, Regards sur l'activité en situation de travail. Contribution à la psychologie ergonomique, Paris, Puf, 1997.

[5] P. Pastré, La conceptualisation dans l'action : bilan et nouvelles perspectives, Education Permanente 139 (1999), 13-36.

[6] P.Pastré, P. Mayen, G. Vergnaud, Note de synthèse sur la didactique professionnelle, Revue Française de Pédagogie 154 (2006), 145-198.

[7] R. Samurçay et P. Rabardel, Modèles pour l'analyse de l'activité et des compétences. Propositions, in : Recherches en didactique professionnelle, R. Samurçay, P. Pastré, eds., Octrès, Toulouse, 2004.

[8] J. Valsiner, Culture in Minds and societies, Sage, New Delhi, 2007.

[9] G. Vergnaud, Au fond de l'action la conceptualisation, in : J.M. Barbier, ed., Savoirs théoriques et savoirs d'action, Puf, Paris, 1996.

[10]P. Vermersch, Describing the practice of introspection, Journal of Counsciousness study 16 (2009), 20-57. 